\title{
DA RUA E DA CENA: UM ESTUDO SOBRE TURISMO DE TEATRO
}

\author{
Maria Manuel Baptista \\ Vanessa Lamego
}

\section{Resumo}

0 presente artigo procura compreender e aprofundar a relação existente entre a festa e o teatro e evidenciar de que modo essa associação pode ser integrada na atividade turística, nomeadamente através do conceito de Turismo de Teatro. Este estudo produz, assim, um levantamento bibliográfico e uma discussão teórica acerca desta temática, onde se concluiu que apesar de não ser evidente a relação entre a festa e o teatro, esta revela-se muito claramente através do ritual e do jogo, dois elementos presentes em ambas as práticas. Com efeito, o sector do turismo não se restringe apenas aos meios de alojamento, transporte e entretenimento, mas também a todas as manifestações culturais que motivam a visita dos turistas. Nestas manifestações podem incluir-se o teatro e a festa, dois elementos que não foram desenhados com o objetivo turístico, mas que possuem grande potencialidade a este nível e que configuram um tipo de turismo cultural que tem vindo a ser designado na literatura da especialidade por Turismo de Teatro.

\section{Palavras-chave:}

Festa; Teatro; Teatralidade; Espetáculo; Turismo de Teatro

\section{Abstract}

This article seeks to understand the relationship between the festival and the theatre and show how this relationship can be integrated in tourist activity, namely through the concept of Theatre Tourism. This study results, thus, in a literature review and a theoretical discussion about these issues, in which was concluded that although the relationship between the festival and the theatre it's not obvious, it is clearly revealed through the ritual and the game, two elements present in both practices. Indeed, the tourism sector is not restricted only to the accommodation, transportation and entertainment segments, but also to the cultural events that motivate tourist's visits. These manifestations may include the theatre and the festival, two elements that were not designed with a tourist purpose, but have a great potential at this level and form a type of cultural tourism that has been designated in the literature as Theatre Tourism.

\section{Keywords:}

Festival; Theatre; Theatricality; Spectacle; Theatre Tourism 


\section{Introdução}

Apesar de não existir ainda muita literatura que fundamente a relação existente entre a festa e o teatro, alguns estudos começam a abordar esta perspetiva, mesmo que de um modo muito abrangente. Assim, o que se verifica é que são muitas as manifestações populares que se têm consolidado a partir da utilização de formas de expressão dramática, podendo, por isso, adotar diferentes designações, tais como 'folclore', 'tradição popular', 'manifestações culturais', 'formas de resistência étnicas', 'formas de expressão artística', 'teatro popular', 'rituais', 'performances', 'manifestações expressivas' ou simplesmente 'cultura' (FRANZONI, 2012).

Estas manifestações populares de carácter dramático são, atualmente, abordadas por duas áreas (a da antropologia e a das artes cénicas) que as classificam de modo diferente. A antropologia considera que estas são "manifestações vivas que mobilizam e articulam atores e significados diversos, sua dramaticidade (...)" (FRANZONI, 2012, p. 52). Por sua vez os estudos em artes cénicas observam que estas manifestações constituem "expressões artístico-culturais marcadas por sua teatralidade e/ou espetacularidade, que podem ser estudadas tanto por seu carácter espetacular e performático, quanto a partir de elementos da técnica e do fazer 'teatral' ali experienciados por aqueles que realizam estas manifestações" (FRANZONI, 2012, p. 52). Apesar das diferenças entre as duas áreas, ambas defendem a utilização da linguagem dramática em manifestações populares, quer sejam mais ou menos tradicionais (FRANZONI, 2012). Com o crescimento da produção académica no campo das artes cénicas, a investigação sobre os aspetos dramáticos das manifestações populares adquiriu novas dimensões, entre as quais se encontra uma nova preocupação com a espetacularização, que começou a ser abordada segundo outras perspetivas (FRANZO$\mathrm{NI}, 2012$ ).

Por outro lado, o teatro tem sido considerado como uma atividade de suporte ao turismo pelas suas qualidades de entretenimento e lazer. (BELLGAM, 2009). Deste modo, apesar de geralmente serem vistas como independentes, as indústrias do teatro e do turismo apresentam características em comum: permitem atrair um elevado número de indivíduos e contribuem para a economia dos locais onde se encontram (BELL-GAM, 2009). Além disso, segundo Bell-Gam (2009), o teatro, tal como o turismo, apresenta grandes potencialidades no que respeita ao desenvolvimento dos destinos, uma vez que este possui qualidades ao nível pedagógico, político, social e económico.

Pelo facto de a investigação nesta área ser ainda recente e reduzida, este artigo pretende ser um contributo a este nível, procurando uma melhor compreensão do que esta complexa temática implica, quer ao nível da dimensão teatral da festa, quer ao nível da sua relação com o turismo. Assim, o presente artigo tem como objetivos compreender e aprofundar a relação existente entre a festa e o teatro e evidenciar de que modo essa associação pode ser utilizada ao nível do turismo, através do conceito de Turismo de Teatro. Para tal, procedeu-se a uma revisão bibliográfica que aborda a dimensão teatral da festa, os conceitos de teatralidade, espetacularidade e performance (noções associadas ao teatro, que permitem explicar a conexão entre o mesmo e a festa) e o modo como esta relação entre a festa e o teatro pode ser utilizada no contexto do turismo, nomeadamente no que concerne ao Turismo de Teatro.

\section{A dimensão teatral da Festa}

A festa surge como um "evento associado ao universo mental e religioso, fruto de uma promessa ou de uma graça alcançada" (SARAIVA \& SILVA, 2008, p. 9), ou seja, como um pretexto para celebrar. Segundo Durkheim (1968), as festas surgiram pela necessidade de separar os dias ou períodos que são destinados às atividades do quotidiano daqueles que se dirigem às atividades sagradas. Esta pode ser estudada segundo várias áreas de conhecimento, procurando cada uma destas abordar o seu conceito (SARAIVA \& SILVA, 2008). Assim, verifica-se uma elevada quantidade de literatura sobre festividades. No entanto, estes estudos geralmente apresentam a descrição minuciosa dos eventos e poucas vezes englobam os contextos sociais e económicos em que ocorrem (AMARAL, 1998).

Neste sentido, várias definições têm sido propostas. Falassi $(1987$, p. 1) considera que uma festa "é um evento, um fenómeno social, encontrado em praticamente todas as culturas humanas". Por sua vez, Getz (1991, p. 54) defende que uma festa é 
uma "celebração pública, independentemente de ter natureza sagrada ou profana, que inclui rituais e comemorações". Hartmann (2011, p. 234) propõe uma definição semelhante ao conceito de 'formas festivas' de Guss (2000): "uma variedade de eventos públicos como Carnaval, paradas, concertos, feiras, quermesses, funerais, festas de santos - procissões, competições esportivas, comemorações cívicas e demonstrações políticas e julgamentos". De um modo geral, observa-se que a festa é considerada como um evento, que pelo seu carácter social e cultural deve ser de acesso livre a toda a população. A festa tem ainda um tema, algo que motiva a sua celebração, sendo que este pode oscilar entre o cerimonial e o festivo, entre o sagrado e o profano.

Com vista à conceptualização do conceito de festa, devem considerar-se dois aspetos fundamentais: a participação e o tempo (AMARAL, 1998). Uma festa pressupõe não só a presença de um público, mas também a sua participação na mesma, sendo este o principal critério que a diferencia do puro espetáculo. No que respeita ao tempo da festa, no limite considera-se que "tudo é festa durante o tempo da festa" (AMARAL, 1998, p. 40). Partindo da questão da participação na festa, Jean Duvignaud (1983) propõe uma nova classificação, dividindo a festa em duas tipologias: as festas de participação e as festas de representação. As festas de participação incluem as cerimónias públicas, nas quais toda a comunidade participa, sendo que os participantes são conscientes dos mitos, símbolos e rituais representados. As festas de representação caracterizam-se por ter 'atores' e 'espetadores'. Os atores, que são geralmente em número restrito, participam diretamente na festa, que é organizada para os espetadores. Estes, por sua vez, participam indiretamente na mesma, pela qual podem ou não ser afetados, atribuindo-Ihe um determinado significado. Quer os espetadores, quer os atores são conscientes da envolvente da festa (rituais, cerimónias e símbolos), entendendo o evento de modo diferente, consoante o papel que Ihes é atribuído. No entanto, Amaral (1998) refere que é possível existir um nível intermédio entre estas categorias propostas por Jean Duvignaud.

Conforme o objeto de estudo ou o tipo de festa em análise, a festa pode ser associada a outros temas. Neste sentido, esta pode ser entendida como um momento ritual, sagrado, relacional e comunitário, e ainda como um instrumento de reprodução de padrões vigentes, relacionado com a procura de significados no passado para o quotidiano e vida social presente

(LUÍNDA, 2001). Considerando a perspetiva da festa como um momento ritual, observa-se que esta é baseada em Turner (1974), uma vez que o autor define a noção de communitas ${ }^{2}$ como conceito articulador da festa. Para Turner (1974) communitas permite demonstrar a posição da festa, bem como de outras manifestações culturais representantes do folclore e da cultura popular. Neste sentido, torna-se necessário compreender, em primeiro lugar, o conceito de ritual. Segundo Victor Turner, Elizabeth Tolbert e, mais recentemente, James MacLynn Wilce, o Homem começou a 'ritualizar' antes mesmo de começar a falar (SCHIAPPA, 2012).

O Ritual pode ser definido como um conjunto de ações organizadas (ritos), executadas, sobretudo, pelo seu valor simbólico, que é prescrito por uma religião ou pelas tradições de uma comunidade. 0 termo exclui, regra geral, ações que são escolhidas arbitrariamente pelos seus executantes, ou ditadas meramente pela lógica, acaso, necessidade, etc. Podemos também dizer que um ritual pode ser executado em ocasiões específicas, ou na intimidade de vários indivíduos ou comunidades. Pode ser levado a cabo por um único indivíduo, por um grupo, ou por uma comunidade inteira; pode acontecer em espaços arbitrariamente escolhidos ou noutros reservados especialmente para o efeito; tanto em público como em privado e/ou, ainda, perante um público específico. Um ritual pode ser restrito a um subgrupo de uma comunidade e pode permitir a passagem entre condições religiosas ou sociais (SCHIAPPA, 2012, p. 66).

O ritual, público ou privado, cria uma perceção diferenciada, dialética e simbólica de aspetos do quotidiano da vida social de um povo (GOMES, 2007). Pela sua natureza simbólica, são diversas as ações que podem ser incorporadas num ritual, nomeadamente gestos, palavras, produção de textos, música, canções, danças, procissões, manipulação de objetos, vestuário, consumo de comida e bebidas, entre outros. Verifica-se, assim, que existe no ritual uma seleção e utilização de determinados elementos, reconhecidos pela comunidade, tal como acontece na festa.

Além disso, é evidente no ritual a presença de diversas características em comum com o teatro. É usual associar o ritual e a festa à origem do te- 
atro, sobretudo no que respeita a manifestações de carácter religioso. Esta ideia tem sido contestada por alguns autores, uma vez que o ritual diz respeito a uma ação complexa que estabelece a ligação entre uma comunidade e a divindade (SCHIAPPA, 2012). No entanto, pode-se afirmar que quer o teatro, quer o ritual integram as mesmas ações simbólicas, visto que se caracterizam por atos comunicativos dirigidos para um ou mais espetadores, tendo ambos como intuito "comunicar alguma coisa" (SCHIAPPA, 2012, p. 69), além de que "o ritual produz um efeito, que mais do que figurativamente mostrado, é realmente produzido na ação" (HUIZINGA, 1990, p. 18).

O ritual encontra-se estritamente associado à sociedade, até mesmo pelo seu papel fulcral no que respeita à organização das comunidades. Do mesmo modo, o teatro pode também ser considerado, para além da vertente artística, como um instrumento cívico. Quando se parte desta ideia, é possível observar duas noções de teatro: teatro enquanto arte e teatro enquanto metáfora da sociedade (SCHIAPPA, 2012). O teatro enquanto arte caracteriza-se pela ficção, mesmo que represente situações reais, e pela presença de espetadores que se deslocam a um espaço com a consciência de que irão assistir a um espetáculo que foi propositadamente elaborado para ser exibido uma ou mais vezes, sabendo que o que está a ser apresentado não é realidade, mas sim uma representação/ficção. Por sua vez, no teatro enquanto metáfora da sociedade o objetivo é mostrar as relações entre os indivíduos e os seus grupos sociais, utilizando um conjunto de normas e convenções que foram apreendidas previamente e que são reproduzidas naquele momento, pelo que o comportamento observado é semelhante ao dos atores que representam um papel e que agem de acordo com um conjunto de indicações e regras adequadas a uma situação em particular. Assim,

se, por um lado, no teatro enquanto arte são representadas ações ou situações inspiradas em comportamentos humanos, por outro, no teatro enquanto metáfora, a construção do Eu social procede de uma aprendizagem de costumes e normas de conduta que diluem o comportamento instintivo, pelo menos no que diz respeito às relações interpessoais e sociais, e o tornam semelhante a uma representação (SCHIAPPA, 2012, p. 71).

Neste sentido, a maior convergência do teatro com o ritual verifica-se precisamente quando este é visto enquanto metáfora da sociedade, visto que várias formas da prática teatral ou parateatral estão diretamente relacionadas com a organização do Homem em sociedade (SCHIAPPA, 2012).

Além do ritual, existem outros elementos que permitem compreender a dimensão mais teatral da festa, como por exemplo o jogo. De acordo com Duvignaud (1983) e Turner (1974), não se deve confundir a festa com o jogo, uma vez que neste último é evidente a utilização de regras e códigos, enquanto na festa o objetivo é destruir toda a regulamentação, sem transgredi-la. Todavia, Huizinga (1990) discorda destes autores e afirma que entre o jogo e a festa existem estreitas relações, já que em ambos predomina a alegria (apesar de a festa também poder assumir um carácter mais sério), são limitados no tempo e no espaço e podem encontrar-se nos dois uma combinação de regras, mas com alguma liberdade.

Também o teatro demonstra uma clara relação com o jogo. O Homem tem, desde sempre, a necessidade do jogo e vontade de 'ser outro', daí afirmar-se que o teatro é, atualmente, uma arte fortemente associada ao fingimento e ao 'fazer de conta'. Além disso, Huizinga (1990) reconhece no jogo duas funções que o aproxima do teatro: 0 jogo é uma luta ou a representação de algo. Representar significa, neste caso, mostrar, podendo também provocar exibições, no sentido de apresentar algo comum, natural ou extraordinário destinado a estimular admiração (SANTOS, 2005).

Verifica-se novamente que a festa apresenta duas vertentes opostas, mas essenciais: a cerimonial e a festiva, sendo que a cerimonial se encontra mais próxima do ritual, enquanto a festiva se relaciona com o jogo, associado também ao divertimento e entretenimento. Deste modo, conclui-se que apesar de não ser evidente a relação entre a festa e o teatro, a articulação é possível através do ritual e do jogo, dois elementos presentes em ambas as práticas.

Por outro lado, anteriormente referiu-se que Jean Duvignaud (1983) propõe uma classificação da festa em festas de participação e festas de representação. Se se considerarem os respetivos conceitos verifica-se que as festas de representação revelam características bastante próximas do teatro, nomeadamente no que respeita à presença de 'atores' (os que organizam e proporcionam o 
espetáculo) e 'espetadores' (os que assistem), ambos conscientes da envolvente da festa (rituais, cerimónias e símbolos), mas que a entendem de modo diferente, atribuindo-lhe, por isso, diferentes significados. Neste sentido, poderia afirmar-se que as festas de representação apresentam uma dimensão teatral.

\section{Teatralidade, Espetacularidade e Performance}

São inúmeras as práticas que numa sociedade, mesmo não sendo consideradas como teatro, são reproduzidas de modo semelhante àquilo que se observa nas práticas teatrais. Estas, geralmente cerimónias ou eventos coletivos, obedecem "a um estudo prévio de espaços e projeção de situações para, num tempo e num local determinados, mediante uma distribuição de funções/papéis específicos, exibirem a representação que resultou dessa mesma elaboração" (SCHIAPPA, 2012, p. 72). Apesar de não se considerar estas práticas como um espetáculo de teatro, pode-se afirmar que, pela sua proximidade a certas características presentes no mesmo, se encontra presente o fator teatralidade.

O conceito de teatralidade surge como "a qualidade do que é teatral, i.e., que participa do teatro ou que procura ter um efeito de teatro" e implica três noções: encenação, representação e espetáculo (SCHIAPPA, 2012, p. 72). O conceito de encenação remete para a prática de pôr em cena, ou seja, refere-se ao "procedimento ou conjunto de procedimentos de articulação dos vários elementos e linguagens envolvidos na criação teatral e cujo resultado se traduzirá no espetáculo, e também a forma e/ou, o ponto de vista sob o qual o espetáculo é construído" (SCHIAPPA, 2012, p. 75). Schiappa (2012) refere ainda que a partir da influência direta que o espetáculo (o que se vê) exerce no espetador (quem vê), é possível compreender melhor o conceito de encenação, que demonstra, assim, ser um processo através do qual alguém constrói uma ação para dar a ver a outros.

No que respeita ao conceito de representação, Stuart Hall (1997, p. 16) refere que "representar alguma coisa é descrevê-la ou dar-lhe uma forma, trazê-la à mente através da descrição ou do retrato ou da imaginação (...) representar também significa simbolizar, substituir, ser uma espécie de alguma coisa ou substituir por outra totalmente diferente". Segundo Schiappa (2012) representar implica apresentar de novo ou substituir por algo que não o original, sendo possível representar uma ideia ou conceito. De um modo geral, "o conceito de representação implica, sobretudo, construção, uma vez que dá origem a algo que não é o objeto ou situação original, mas que surge em seu lugar, ou pelo menos como uma síntese do mesmo" (SCHIAPPA, 2012, p. 74).

Finalmente, o espetáculo é, geralmente, associado a tudo o que é apresentado para ser contemplado (DUMAS, 2010). A palavra espetáculo provém do latim spectaculum e apresenta-se como algo que solicita, atrai a atenção do olhar e permite despertar emoções (REY, 1998). Esta palavra deriva ainda da sua forma infinitiva spectare que tem como significado olhar, observar e contemplar (SCHIAPPA, 2012; DUMAS, 2010).

Considerando a evolução deste conceito, constata-se que no final do século XIII, a palavra spectaculum era associada ao divertimento que se apresentava ao público, passando pouco depois a designar "qualquer representação teatral" (VASCONCELLOS, 2009, p. 108). No século XVI, o espetáculo começa a ser sinónimo de teatro (PIERRON, 2002). Verifica-se, assim, desde cedo, uma forte ligação do espetáculo ao teatro, até porque o teatro "é uma entre as mil invenções espetaculares da humanidade" (PRADIER, 1999, p. 8). Na perspetiva teatral, o espetáculo é um género que integra, por um lado, as artes de representação (dança, ópera, cinema, mímica e teatro) e por outro, as artes da cena (desportos, ritos, touradas, entre outros), sendo que nas artes da cena o que é visto é a realidade, enquanto nas artes de representação observa-se um mundo imaginário com diferentes realidades (SANTOS, 2005).

Nesse aspeto os espetáculos parecem se prestar de maneira exemplar à função paradigmática. Não são eles, afinal, não apenas a conjugação das duas formas de linguagem - a linguagem da voz e a do gesto - e, portanto, o veículo de comunicação mais poderoso, mas, mais do que isso, não contém eles na sua própria estrutura essencial as duas faces de toda manifestação? Não há de fato espetáculo sem a presença simultânea, no seu evoluir, do dizer e do fazer, do representar e do agir, do dissimular e do revelar (FORTES, 1997, p. 32). 
A partir da palavra espetáculo encontram-se outras designações, como é o caso do termo 'espetacular', que pode ser entendido como "uma forma de ser, de se comportar, de se movimentar, de agir no espaço, de se emocionar, de falar, de cantar e de se enfeitar, que se distingue das ações banais do cotidiano" (PRADIER, 1999, p. 7). Espetacular pode também significar o oposto do que é comum, algo sem grandes atrativos para atrair a perceção do outro (DUMAS, 2010). As formas de comportamento consideradas como espetaculares relacionam-se com o "jogo estético de um acontecimento que, ao ser executado, se completa na recepção do objeto por uma plateia que assiste, que contempla, que dialoga com o que é apresentado" (DUMAS, 2010, p. 2). Estas podem ser observadas em cerimónias, festejos, rituais religiosos e folguedos, ou seja, nas tradições culturais que envolvem algum padrão característico da representação de um determinado enredo (GOMES, 2007). Estas manifestações possuem sentido próprio que é expresso através de elementos como a dança, a música, os figurinos e figuras representativas, que "colocam em cena um enredo cuja narrativa expressa o imaginário coletivo, a realidade social e a história de vida dos praticantes de cultura" (GOMES, 2007, p. 61). Além disso, nestas manifestações populares tradicionais os grupos culturais revelam os seus conhecimentos, mitos, crenças e rituais, apresentando-os como 'brincadeiras' e permitindo, deste modo, a recriação destes eventos (festas, peditórios, folguedos, cortejos, entre outros) (GOMES, 2007).

O significado do conceito de teatralidade assenta no conjunto dos três conceitos que acabámos de referir (encenação, representação, espetáculo), uma vez que para obter um efeito de teatro tem de haver uma forma específica de organizar no espaço e no tempo (encenação) a representação de alguma ação (a criação do seu simile) para ser exibida e vista por um ou mais espetadores (espetáculo), veiculando, deste modo, ações e situações humanas que, podendo ou não estar sujeitas ao modo narrativo e ao regime ficcional, constituem performances, ou seja, ações concretas e reais (SCHIAPPA, 2012, p. 75).

Um dos conceitos que contribuiu para o incremento dos estudos do teatro e, consequentemente, da teatralidade foi o conceito de performance. De acordo com SCHIAPPA (2012), esta designa- ção surge associada à ação que ocorre durante um espetáculo, nomeadamente no que respeita à qualidade do desempenho de um ator. No entanto, o conceito de performance encontra-se diretamente relacionado com a ação encenada para produzir um efeito de teatro, ou seja, a teatralidade (SCHIAPPA, 2012).
Antes de ocorrer associada ao desempenho do ator, durante o espetáculo, a performance está im- plícita durante o processo de teatralização exata- mente pelo facto de, enquanto conceito, o termo implicar um funcionamento pré estabelecido, uma préformance. É a partir dessa préformance que $O$ ator irá estabelecer a sua performance (SCHIAP- PA, 2012, p. 81).

Para caracterizar uma performance, é preciso que algo aconteça num determinado instante e espaço (HUAPAYA, 2007). Segundo o autor, a exibição pura e simples de um filme, por exemplo, não caracteriza uma performance, a menos que esse filme seja inserido num determinado contexto e exibido ao mesmo tempo como um espetáculo. RoseLee Goldberg (1988) acrescenta que a performance pode ser abordada por diversas áreas como a história de arte, a filosofia, a sociologia, a antropologia, a fotografia, o teatro, a dança, o candomblé, a arquitetura e a música.

\begin{abstract}
Segundo os princípios atuais da teoria crítica, o espetador de arte, o leitor, de um texto, o público de um filme ou de uma produção teatral são todos performers e intérpretes. Pois, as nossas reações são imediatas e vivas diante de uma obra de arte, são essencialmente interpretações contínuas (GOLDBERG, 1998, pp. 9-10).
\end{abstract}

Assim, para o estudo da performance vários autores têm deixado o seu contributo. Marvin Carlson (1996) defende que nas décadas de 60 e 70 as ciências sociais, a antropologia e a sociologia contribuíram consideravelmente para o estudo da performance, através da convergência terminológica. 0 autor acrescenta ainda que:

(...) a função da performance dentro de uma cultura, o estabelecimento e o uso de contextos performativos particularmente designados, a relação do performer para com a performance e a geração e operações de performances realizadas sobre ou influenciadas por várias culturas diferentes são as questões que contribuíram enormemente para o pensamento contemporâneo sobre o que a performance e como é que esta opera (CARLSON, 1996, p. 33).

Milton Singer $(1959,1972)$ criou a designação de performances culturais, definida como formas de 
expressão artística e cultural que possuem como características uma duração limitada, um horário definido (de princípio e fim), um programa de atividades, um grupo de performers, espetadores e um espaço e ocasião para a sua realização e que podem ser expressas através de diversos meios de comunicação, como narrações, canto, dança, artes visuais, entre outros. 0 autor refere ainda que as manifestações que se inserem nesta categoria podem incluir o teatro tradicional, a dança, os concertos, os recitais, os festivais religiosos e os casamentos. Victor Turner (1974) também contribuiu para o estudo da performance, através dos conceitos de liminaridade, liminalidade e liminóide, pelo que a liminaridade é considerada, pelo autor, como um momento comum ao ritual, à cerimónia e ao teatro.

Deste modo, se se considerar o teatro como uma performance e o mundo como uma metáfora teatral, verifica-se que toda e qualquer performance, mesmo que não seja teatro de acordo com o seu conceito tradicional, é uma ação repleta de teatralidade, "uma vez que é encenada (se, por cena, compreendermos o espaço delimitado onde algo acontece sob o olhar de alguém) ou construída de forma pré-determinada, mesmo que não encerre uma narrativa ou uma ficção" (SCHIAPPA, 2012, p. 84).

A partir do campo das artes do espetáculo e do estudo das performances surge uma nova disciplina de investigação denominada de Etnocenologia: "a etnocenologia amplia o estudo do teatro ocidental para as práticas espetaculares do mundo inteiro, em particular aquelas que se originam do rito, do cerimonial, das cultural performances" (PAVIS, 1999, p. 152). Segundo Jean-Marie Pradier (1996, p. 16), fundador do conceito de etnocenologia, esta disciplina consiste no "estudo nas diferentes culturas das práticas e dos comportamentos humanos espetacularmente organizados". Entre os fatores que contribuíram para o seu surgimento encontram-se o interesse por formas teatrais não ocidentais; a reavaliação das artes do circo, da dança, da bioarte e da street dance; o crescimento dos estudos na área, nomeadamente no que respeita às temáticas dos ritos, rituais, xamanismo e cerimónias; o desenvolvimento dos estudos de etnomusicologia; e a ação institucional desenvolvida por organismos como a UNESCO, a Maison des Cultures du Monde, a International
School of Theatre Antrhropology e o Centre for Performance Research of Cardiff (GUINSBURG, FARIA \& LIMA, 2006).

Armando Bião (2011) propõe uma classificação para a etnocenologia através de três objetos espetaculares: objetos substantivos (as artes do espetáculo), objetos adjetivos (ritos espetaculares) e objetos adverbiais (formas quotidianas espetacularizadas pelo olhar do investigador). Segundo o autor o primeiro subgrupo corresponde aos objetos que são "criados, produzidos e pensados pelas comunidades nas quais ocorrem, como atos explicitamente voltados para o gozo público e coletivo (...)", pelo que a sua função é o divertimento, o prazer, a fruição estética e o conforto comunitário (BIÃO, 2011, p. 112). Este inclui as diversas artes do espetáculo, nomeadamente o teatro, a dança, a ópera, o circo, a música cénica, o happening, a performance e o folguedo popular, também conhecido como danças dramáticas. Os objetos adjetivos ou ritos espetaculares são os fenómenos que, mesmo sem possuirem de modo explícito as características referidas nos objetos substantivos, também envolvem formas sociais de representação semelhantes às do teatro e da ópera, sobretudo em relação às "formas de padrões corporais ritmados, como os compartilhados com a dança e a música cênica, formas de brincadeira comunitária, assim como certos folguedos, e formas de ações coletivas envolvendo o prazer do testemunho do risco físico, como as artes circenses (BIÃO, 2011, p. 112). Ou seja, este subgrupo inclui os rituais religiosos e políticos e os festejos públicos, que segundo a terminologia de Durkheim (1968) correspondia ao campo dos ritos representativos ou comemorativos. No último grupo inserem-se "os fenômenos da rotina social que podem se constituir em eventos, consideráveis, a depender do ponto de vista de um espetador, como espetaculares, a partir de uma espécie de atitude de estranhamento que os tornaria extraordinários (...)" (BIÃO, 2011, p. 113). Assim,

(...) o objeto espetacular não é mais apenas um
ponto fixo: uma festa, um rito, uma dança ou uma
peça de teatro ou qualquer outro espetáculo, ele
se desloca para um lugar móvel, o "olhar" ou os
sentidos que se estabelecem entre um determina-
do objeto e quem se dispõe a pesquisá-lo (DUMAS,
2010, p. 3).

De um modo geral, a etnocenologia tem contribuído para o aumento do conhecimento científico e 
artístico ao nível das artes do espetáculo, não só no que respeita ao teatro, à dança, ao circo, à ópera, ao happening e à performance, mas também relativamente aos rituais, aos fenómenos sociais extraordinários e até mesmo aos modos de vida do quotidiano, quando considerados como fenómenos espetaculares (BIÃO, 2011). Assim, é comum dizer-se que esta disciplina se relaciona com vários campos de saber, nomeadamente as ciências humanas interessadas na teatralidade quotidiana e na metáfora do espetáculo, as etnociências, a etnometodologia, a antropologia teatral e os estudos da performance (BIÃO, 2011).

Em suma,

(...) se, como vimos, a teatralização está presente na maioria das ações humanas, então, quase tudo o que fazemos, conduz a um determinado efeito ou resultado. Isto significa que pensamos sempre considerando o que vai ser visto e se irá ser aceite ou não. Isto significa que não existem ações humanas "públicas", i.e., performances, que não tenham um espetador e por isso não sejam "encenadas" ou não sejam teatrais, construídas e praticadas para serem vistas (SCHIAPPA, 2012, p. 85).

É possível, assim, concluir que qualquer cerimónia e apresentação pública é um ato repleto de teatralidade e que obedece às mesmas características e procedimentos que um espetáculo de teatro para os espetadores.

\section{A Festa enquanto produto do Turismo de Te- atro}

As festas são parte integrante de todas as sociedades: estas celebram o património cultural e a identidade, do mesmo modo que proporcionam oportunidades de revitalização das comunidades e o desenvolvimento do comércio e do emprego (FERDINAND \& WILLIAMS, 2013). Além disso, as festas são ainda um importante segmento ao nível do mercado turístico (PICARD \& ROBINSON, 2006).

Apesar disso, Christian Oliveira (2007, p. 24) afirma que "(...) nenhuma festa pode, 'naturalmente', ser considerada um atrativo turístico", o que se observa especialmente ao nível das festas populares (tradicionais e/ou religiosas), uma vez que para o povo a festa nunca é turística, já que não é realizada com fins profissionais. Denota-se, assim, uma clara resistência por parte das festas populares em relação ao turismo, e consequentemente, à sua promoção enquanto evento turístico (OLI-
VEIRA, 2007).

No entanto, para o turismo, que funciona como um sistema aberto (BENI, 2000) e que se move pela variedade de oferta nos destinos, qualquer manifestação cultural pode constituir parte de um produto turístico, desde que seja associada de forma direta ou complementar aos restantes serviços turísticos (RIBEIRO, 2004). O sector do turismo não se restringe apenas aos serviços de alojamento, entretenimento e meios de transporte (OLIVEIRA, 2007), sendo composto por elementos primários e secundários (HUGHES, 1998). Destes, conclui-se que a festa e os espetáculos (associados à cultura e aos eventos) podem constituir uma motivação para visitar um destino, sendo geralmente identificados como elementos primários do mesmo (LAW, 1993).

Apesar disso, a transformação de uma festa em atrativo turístico é algo complexo e que pode conduzir a profundas tensões, uma vez que é necessário "manter a ambiguidade simbólica que fortalece a festa pelas [suas] dimensões sagradas e profanas [...] [e, por outro lado,] é preciso compreender o estágio do jogo de interesses que estabelece escolhas discriminatórias para festejos de natureza semelhantes". (OLIVEIRA, 2007, p. 27).

Considerando que as festas e as celebrações populares se referem a momentos diferenciadores da vida quotidiana, permitindo atrair um público consumidor específico (os turistas), torna-se necessário compreender as interações que se estabelecem quando os bens simbólicos se inserem no mercado turístico (CARVALHO \& BLÓS, 2012). Deste modo, a introdução da festa e das práticas culturais na atividade turística suscita questões relacionadas com a "autenticidade dos eventos, festas e celebrações, a espetacularização das tradições e a ressemantização dos seus significados sob a égide da fragmentação ou dissolução das identidades globais" (CARVALHO \& BLÓS, 2012, p. 110). Sabe-se que aos visitantes é apenas proporcionada a representação e o espetáculo, uma vez que estes "não têm tempo para a autenticidade e deliciam-se com a natureza simulacional e construída do turismo contemporâneo, que sabem ser apenas um jogo" (FEATHERSTONE, 1995, p. 144). Como tal, a partir do momento em que uma manifestação cultural é formatada para uma apresentação de carácter turístico, as fronteiras entre o ritual e o jogo cénico da performance turística 
diluem-se (CARVALHO \& BLÓS, 2012). De acordo com Araújo (2001, p. 59),

na condição de espectador, o turista acabaria por percorrer lugares facilmente reconhecíveis, devidamente preparados e encenados [...]. A busca pelas experiências autênticas leva a que o turista possa acreditar que o que está experimentando seja de fato autêntico, uma vez que os bastidores preparados para [a] sua visitação são apreciados como sendo 'originais'.

O interesse de exploração turística de uma determinada manifestação cultural deve-se, assim, a fatores como o potencial, a originalidade e a divulgação consistente da mesma (RIBEIRO, 2004). Apesar disso, de acordo com Ribeiro (2004), para que a festa seja considerada como produto turístico, esta tem de ser capaz de atrair não apenas devotos, como é o caso das festas religiosas, mas também outros segmentos, pelo que a partir deste momento a estrutura física da festa se altera, sofrendo um possível redimensionamento do espaço e dos serviços.

No momento em que a festa interessa a agentes privados que formalizam [a] sua comercialização, ela passa a compor junto com outros eventos populares um produto cultural turístico [...] Contribui para isso a imagem da festa e o potencial de atrair determinados públicos que possuam afinidades com o evento ou mesmo se movam pela motivação da simples curiosidade (RIBEIRO, 2004, p. 48).

Apesar da atividade turística não constituir a razão de ser da festa, é evidente a existência de uma forte relação entre a mesma e o turismo: as festas contribuem para a redução da sazonalidade, geram receitas para o Estado (RITCHIE \& BELIVEAU, 1974) e proporcionam impactes económicos muito positivos nas economias dos locais, através da criação de receitas turísticas, dando suporte aos negócios existentes e encorajando o aparecimento de novas start-ups (MITCHELL \& WALL, 1986; O'SULLIVAN \& JACKSON, 2002). Desta relação surge um novo produto turístico: o turismo de festas. O'Sullivan e Jackson (2002) definem-no como a visita de um determinado local durante o período da festa, por parte de pessoas não residentes nesse local. Quinn (2006) acrescenta que nesta definição deve ter-se em consideração que as festas procuram funcionar como atrações turísticas, que os turistas se encontram indiscutivelmente atraídos por festas e que é evidente a existência de uma relação entre o crescimento das festas e a procura turística. Apesar da crescente importân- cia que o turismo de festas tem ganho na literatura nos últimos anos (QUINN, 2006), a grande maioria dos estudos diz apenas respeito ao seu impacte económico ou às motivações pelas quais as pessoas frequentam as festas (GURSOY, KIM \& UYSAL, 2004). No entanto, a festa não se insere apenas na tipologia do turismo de festas. Consoante à temática da festa, a interpretação que é atribuída à mesma ou até mesmo o tipo de público que atrai, a festa pode assumir diferentes classificações ao nível do turismo, tais como turismo de eventos, turismo criativo, turismo de experiências, turismo de entretenimento e turismo de teatro. Importa ainda referir que todos estes produtos turísticos se inserem na categoria do turismo cultural.

Destas tipologias, importa especialmente para esta investigação o turismo de teatro. Como se observou anteriormente, a festa embora não possa ser vista exclusivamente como teatro, apresenta-se como um momento repleto de teatralidade, que obedece às mesmas características e procedimentos de um espetáculo de teatro. Assim, quando se considera que a visita e/ou participação numa determinada festa teve como motivação a sua dimensão teatral, pode assumir-se que os visitantes estão a praticar turismo de teatro, uma vez que:

nas festas, as lentes dos turistas [...] são atraídas, também, por personagens, alegorias, fantasias, excentricidades, ou seja, elementos visuais, característicos da sociedade moderna, [...] tornando-se um atrativo para as pessoas de fora, sendo a imagem um dos elementos fundamentais impulsionadores da cultura de consumo (ROSA, 2002, p. 35).

É, assim, indiscutível a relação existente entre o teatro e o turismo. Esta relação tem sido abordada em alguns estudos, sobretudo no que respeita à identificação dos visitantes nas audiências de teatro e à determinação da influência do teatro na decisão de visitar um destino (HUGHES, 1998). No entanto, esta temática é ainda recente e carece de uma maior investigação. Esta relação pode ser explicada a partir do conceito de turismo de teatro (theatre tourism). Como se observa na figura 1, para entender o conceito de turismo de teatro torna-se relevante compreender os conceitos de turismo de interesse especial, turismo cultural e turismo de artes.

O turismo de interesse especial verifica-se quando “a motivação do visitante e o processo de decisão 
Figura 1 - Conceptualização do Turismo de Teatro

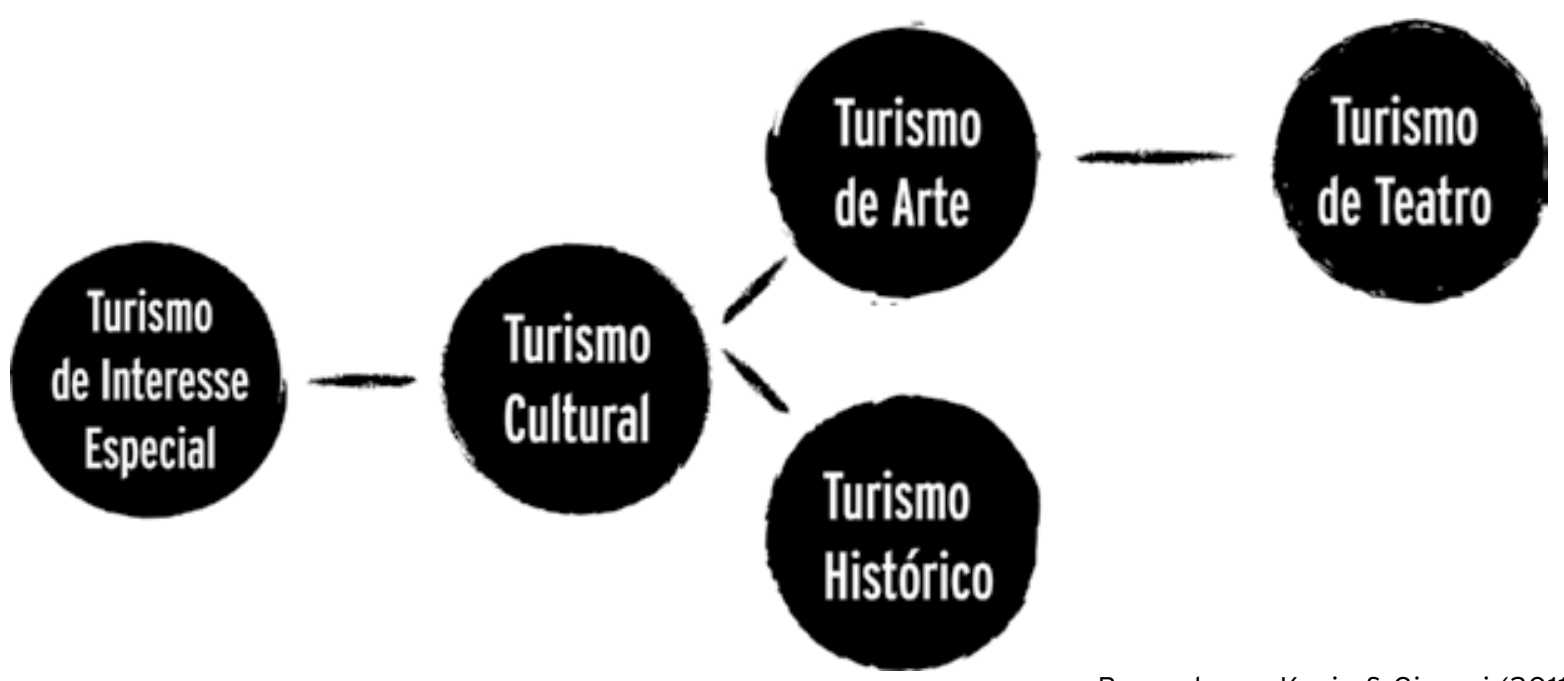

Baseado em Kruja \& Gjyrezi (2011) e Hughes (1995)

são essencialmente determinados por um interesse especial que pode ser ao nível da(s) atividade(s) e/ou dos destinos" (HALL \& WEILER, 1992, p. 5). Este tipo de turismo compreende, assim, as diferentes formas de viagem, ditas de interesse especial, também conhecidas como nichos de mercado, nomeadamente o turismo de aventura, o turismo rural, o turismo cultural, o turismo religioso, o ecoturismo, o turismo gastronómico, o turismo selvagem, o turismo patrimonial e o turismo médico (KRUJA \& GJYREZI, 2011). Trauer (2006) inclui também o turismo de festas e eventos como uma forma de turismo de interesse especial. De um modo geral, o propósito destes produtos turísticos é proporcionar a oportunidade de usufruir de um destino ambiental e culturalmente rico, bem conservado, pouco frequentado e com locais onde ainda é possível disfrutar de um pouco de tranquilidade, ou seja, o oposto do turismo de massas (TRAUER, 2006; KRUJA \& GJYREZI, 2011).

Destas formas de turismo de interesse especial interessa especialmente para esta investigação o turismo cultural. Muitos dos produtos culturais são suficientemente atraentes para que se desenvolva uma indústria de turismo (ASHWORTH \& DIETVORST, 1995), pelo que a cultura e os recursos culturais têm cada vez mais um papel central na atração de visitantes para um determinado destino (MCKERCHER, HO \& CROS, 2005; CHAI, 2011; ALBERTI \& GIUSTI, 2012). O turismo cultural consiste, assim, "num género de turismo de interesse especial baseado na procura e participação em experiências culturais, sejam estas estéticas, inte- lectuais, emocionais ou psicológicas" (STEBBINS, 1996, p. 948). Esta definição inclui uma grande variedade de formas culturais, incluindo a história, a religião, a arte, a arquitetura e outros elementos que contribuem para a formação da cultura dos destinos (KRUJA \& GJYREZI, 2011). Dentro deste conceito é ainda possível identificar diferentes níveis de motivação, sendo que no nível mais motivado pela cultura dos destinos se encontram os visitantes que procuram conhecer um destino precisamente pelas suas oportunidades de teatro (SILBERBERG, 1995). Todavia, Hughes (1995) propõe uma subdivisão deste conceito em turismo de artes e turismo histórico. Segundo o autor, o turismo de artes será aquele cuja principal atração são as representações. Este tipo de turismo compreende ainda as experiências dos visitantes baseadas: (a) nas artes performativas, nas artes visuais, na literatura, no design e na música, e (b) no turismo criativo, considerando a ativa participação no processo criativo das artes (TOURISM TASMANIA, 2012). Esta forma de turismo pode ainda incluir os eventos relacionados com as diferentes artes (TOURISM TASMANIA, 2012).

É neste contexto que se aborda o turismo de teatro, sendo que, na verdade, este não é mais do que a interligação entre o turismo cultural e o turismo de artes. O turismo de teatro pode ser explicado através do conceito de theatrical performances. Considerado como um novo produto turístico-cultural, este conceito é constituído pelas performances de grande escala realizadas ao vivo, que podem ocorrer indoor ou outdoor e 
são delineadas predominantemente para turistas (SONG \& CHEUNG, 2010). Apesar de este conceito estar a ganhar popularidade, uma vez que este tipo de performances permite atrair um elevado número de visitantes, e por isso, apresenta importantes impactes ao nível da economia dos destinos, são ainda escassos os estudos que abordam esta dimensão turística do teatro (SONG \& CHEUNG, 2010, 2012). A noção de theatrical performances pode ainda ser considerada como um tipo de entretenimento e, nesse sentido, como um procedente do turismo de entretenimento (SONG \& CHEUNG, 2012). De acordo com Hughes (2000), o entretenimento inclui performances ao vivo de música, dança, espetáculos e peças de teatro, idas ao cinema, bares, discotecas e eventos desportivos, ver televisão, jogar jogos de computador e ouvir música (CD's). Importa referir que Ryan e Collins (2008) foram os primeiros a analisar a construção do teatro enquanto meio de entretenimento. Além disso, no contexto do turismo, o teatro é, geralmente, visto como uma motivação de férias, lazer e recreio, por nesta categoria se incluírem os eventos culturais e as atividades de recreio e entretenimento (OMT, 2010). No entanto, torna-se necessária a realização de estudos críticos mais aprofundados acerca desta temática para compreender em que condições pode o teatro realmente ser compreendido, pela sua própria natureza, enquanto mera actividade de entretenimento.

Apesar da evidente importância do teatro para a indústria turística, a sua relação ainda se encontra pouco estudada e os seus conceitos pouco aprofundados. Pela dificuldade em encontrar uma definição clara de turismo de teatro, no âmbito desta investigação definiu-se o mesmo como aquele que ocorre quando o visitante viaja tendo como principal motivação o teatro, sendo que o teatro pode assumir, neste sentido, várias interpretações.

\section{Conclusão}

Nesta investigação observou-se que são inúmeras as práticas que numa sociedade, mesmo não sendo consideradas teatro, são reproduzidas de modo semelhante àquilo que se observa nas práticas teatrais. Entre estas pode incluir-se a festa, uma manifestação que apresenta duas vertentes opostas, mas essenciais: a cerimonial e a festiva.
Apesar de não ser evidente a relação entre a festa e o teatro, esta pode ser observada através do ritual e do jogo, sendo que o ritual se encontra mais próximo da vertente cerimonial, enquanto que o jogo, em conjunto com o divertimento e o entretenimento, se relaciona com a vertente festiva. Além disso, através dos conceitos de teatralidade, espetacularidade e performance, denota-se que qualquer cerimónia e/ou apresentação pública é um ato repleto de teatralidade e que obedece às mesmas características e procedimentos que um espetáculo de teatro para os espetadores.

Conclui-se ainda que apesar da resistência por parte das festas em relação ao turismo, e consequentemente, à sua promoção enquanto evento turístico, a festa e os espetáculos podem constituir uma motivação para visitar um destino, sendo geralmente identificados como elementos primários do mesmo. Consoante à temática da festa, a interpretação que é atribuída à mesma ou o tipo de público que atrai, a festa pode assumir diferentes classificações ao nível do turismo, tais como: turismo de festas, turismo de eventos, turismo criativo, turismo de experiências, turismo de entretenimento e turismo de teatro, sendo de realçar que todos estes produtos turísticos se inserem na tipologia do turismo cultural. Destas tipologias importa especialmente o turismo de teatro que, no âmbito desta investigação, é definido como aquele que ocorre quando o visitante viaja tendo como principal motivação o teatro, sendo que o conceito de teatro pode assumir, neste contexto, várias interpretações. Por último, conclui-se que quando a visita e/ou participação numa determinada festa tem como motivação a sua dimensão teatral, se assume que os visitantes estão a praticar turismo de teatro.

\section{Referências}

ALBERTI, F.; GIUSTI, J. Cultural heritage, tourism and regional competitiveness: the Motor Valley cluster. City, Culture and Society, v. 3, 261-273, 2012.

AMARAL, R. Festa à Brasileira. Significados do festejar, no país que "não é sério". 1998. 380 f. Tese (Doutorado em Antropologia Social) - Universidade de São Paulo, São Paulo, Brasil. 1998.

ARAÚJO, S. M. Artifício e autenticidade: o tu- 
rismo como experiência antropológica. In: BANDUCCl, A. \& BARRETTO, M. (Orgs.). Turismo e identidade local: uma visão antropológica. São Paulo: Papirus, 2001, pp. 49-63.

ASHWORTH, G. J.; DIETVORST, A. G. J. Tourism and Spacial Transformations. Wallingford: $C A B$ International, 1995.

BELL-GAM, H. L. Strategies for the development of tourism and theatre industries in Nigeria: Rivers State Perspective. The Criative Artist: A Journal of Theatre and Media Studies, v. 3, n. 1, 1-18, 2009.

BENI, M. C. Análise estrutural do turismo. São Paulo: SENAC, 2000.

BIÃO, A. A vida ainda breve da etnocenologia: uma nova perspetiva transdisciplinar para as artes do espetáculo. Cátedra de Artes, n. 10, 106123, 2011.

CARLSON, M. Performance: a critical introduction. London \& New York: Routledge, 1996.

CARVALHO, C. L. Turismo no Brasil e no Mundo: tendências e megatendências. 2004. Trabalho apresentado à Aula Magna UNIFACS, Universidade Salvador, Brasil, 2004.

CHAI, L. Culture Heritage Tourism Engineering at Penang: Complete The Puzzle of "The Pearl of Orient". Systems Engineering Procedia, v. 1, 358-364, 2011.

DUMAS, A. G. Etnocenologia e comportamentos espetaculares: desejo, necessidade e vontade. 2010. Trabalho apresentado ao VI Congresso de Pesquisa e Pós-Graduação em Artes Cénicas, São Paulo, 2010.

DURKHEIM, E. Les formes élémentaires de la vie réligieuse. Paris: PUF, 1968.

DUVIGNAUD, J. Festas e civilizações. Rio de Janeiro: Tempo Brasileiro, 1983.

FALASSI, A. Time out of time: essays on the festival. Albuquerque: University of New Mexico Press, 1987.

FEATHERSTONE, M. Cultura de consume e pósmodernismo. São Paulo: Studio Nobel, 1995.

FERDINAND, N.; WILLIAMS, N. International fes- tivals as experience production systems. Tourism Management, v. 34, 202-210, 2013.

FIGUEIREDO, J. O Fenómeno da Co-Presença na Comunicação Teatral Contemporânea e sua Repercurssão no Marketing de Vendas Directas. 2000. 123 f. Dissertação (Mestrado em Ciências da Comunicação) - Universidade Fernando Pessoa, Porto, Portugal. 2000.

FORTES, L. R. S. Paradoxo do Espetáculo. São Paulo: Discurso Editorial, 1997.

FRANZONI, T. M. Artes cênicas e antropologia: um diálogo a partir das manifestações populares de carácter dramático. DA Pesquisa - Revista do Centro de Artes da UDESC, n. 9, 51-63, 2002.

GETZ, D. Festivals, special events and tourism. New York: Van Nostrand Reinhold, 1991.

GOLDBERG, R. Performance Art: from futurism to the present. London: Thames \& Hudson Ltd, 1988.

GOMES, C. C. S. 0 ritual e o lúdico nas tradições culturais: poéticas e performances. In: V COLÓQUIO INTERNACIONAL DE ETNOCENOLOGIA, 2007, Salvador. Anais do V Colóquio Internacional de Etnocenologia, Salvador: Fast Design, 2007, pp. 61-68.

GUINSBURG, J.; NETTO, J.; CARDOSO, R. Semiologia do Teatro. São Paulo: Editora Perspectiva, 1988.

S.; FARIA, J. R.; LIMA, M. A. Dicionário do Teatro Brasileiro: temas, formas e conceitos. São Paulo: Perspectiva, 2006.

GURSOY, D.; KIM, K.; USYAL, M. Perceived impacts of festivals and special events by organizers: an extension and validation. Tourism Management, v. 25, 171-181, 2004.

HALL, C. M.; WEILER, B. Introduction: what's so special about special interest tourism? In: WEILER, B. \& HALL, C. M. Special Interest Tourism. London: Bellhaven Press, 1992, pp. 1-14.

S. The work of representation. In: HALL, S. (Org.). Representation: Cultural representations and signifying practices. London: Sage Publications, 1997, pp. 13-74.

HARTMANN, L. Performances culturais: expres- 
sões de identidade nas festas da fronteira entre Brasil, Argentina e Uruguai. Etnográfica, v. 15, n. 2, 233-259, 2011.

HUAPAYA, C. Performance, tecido performativo, cultura orgânica do espaço. In: V COLÓQUIO INTERNACIONAL DE ETNOCENOLOGIA, 2007, Salvador. Anais do V Colóquio Internacional de Etnocenologia, Salvador: Fast Design, 2007, pp. 69-74.

HUGHES, G. Authenticity in tourism. Annals of Tourism Research, v. 22, n. 4, 781-803, 1995.

HUGHES, H. Arts, Entertainment and Tourism. Oxford: Buttherworth Heinemann, 2000.

$H$. Theatre in London and the inter-relationship with tourism. Tourism Management, v. 19, n. 5, 445-452, 1998.

HUIZINGA, J. Homo Ludens. São Paulo: Perspectiva, 1990.

KRUJA, D.; WALL, G. The Special Interest Tourism Development and the Small Regions. Turizam, v. 15, n. 2, 77-89, 2011.

LAW, C. M. Urban Tourism - Attracting Visitors to Large Cities. London \& New York: Mansell, 1993.

LUÍNDA, L. E. A. Festas, Festas de Santo: Rituais Amazônicos. 2001. Trabalho apresentado ao XXIV Congresso Brasileiro da Comunicação, Campo Grande, Mato Grosso do Sul, 2001.

MCKERCHER, B.; HO, P.; CROS, H. Relationship between tourism and culture heritage management: evidence from Hong Kong. Tourism Management, v. 26, 539-548, 2005.

MITCHELL, C.; WALL, G. Impacts of cultural festivals on Ontario communities. Recreation Research Review, v. 13, n. 1, 28-37, 1986.

O'SULLIVAN, D.; JACKSON, M. Festival Tourism: a contribution to sustainable local economic development? Journal of Sustainable Tourism, v. 10, n. 4, 325-342, 2002.

OLIVEIRA, C. D. M. Festas populares religiosas e suas dinâmicas espaciais. Mercator - Revista de Geografia da UFC, v. 6, n. 11, 23-32, 2007.

OMT. International Recommendations for Tou- rism Statistics 2008. New York: United Nations, 2010.

PAVIS, P. Dicionário de Teatro. São Paulo: Perspectiva, 1999.

PICARD, D.; ROBINSON, M. Remaking worlds: festivals, tourism and change. In:

Festivals, tourism and social change: remaking worlds. Clevedon: Chanel View Publications, 2006, pp. 1-31.

PIERRON, A. Dictionnaire de la Langue du Théâtre. Paris: Le Robert, 2002.

J. M. Ethnosceénologie: la profundeur des émergences. Internationale de l'imagineire, n. 5, 13-41, 1996.

J. M. Etnocenologia. In: BIÃO, A. \& GREINER, C. (Orgs.). Etnocenologia: textos selecionados. São Paulo: Annablume, 1999, pp. 7-13.

QUINN, B. Problematising 'Festival Tourism': arts festivals and sustainable development in Ireland. Journal of Sustainable Tourism, v. 14, n. 3, 288-306, 2006.

REY, A. Le Dictionnaire Historique de la Langue Française. Paris: Le Robert, 1998.

RIBEIRO, M. Festas populares e turismo cultural - inserir e valorizar ou esquecer? 0 caso dos Moçambiques de Osório, Rio Grande do Sul. PASOS - Revista de Turismo y Patrimonio Cultural, v. 2, n. 1, 47-56, 2004.

RITCHIE, J.; BELIVEAU, D. Hallmark events: an evaluation of strategic response to seasonality in the travel market. Journal of Travel Research, v. 13, n. 2, 14-20, 1974.

ROSA, M. C. Apresentação. In: Festa, lazer e cultura. São Paulo: Papirus, 2002, pp. 7-42.

RYAN, C.; COLLINS, A. B. Entertaining international visitors: the hybrid nature of tourism shows. Tourism Recreation Research, v. 33, n. 2, 143-149, 2008.

SANTOS, E. C. M. Religião e Espetáculo: análise da dimensão espetacular das festas públicas do candomblé. 2012. 229 f. Tese (Doutorado em Antropologia Social) - Universidade de São Paulo, São Paulo, Brasil. 2012. 
SARAIVA, A. L.; SILVA, J. C. Espacialidade das festas religiosas em comunidades ribeirinhas de Porto Velho, Rondônia. Espaço e Cultura, n. 24, 7-18, 2008.

SCHIAPPA, B. A dimensão teatral do Auto da Fé. 2012. 151 f. Tese (Doutorado em Estudos Artísticos) - Universidade de Lisboa, Lisboa, Portugal. 2012.

SEIDL, R. 0 negócio do ócio: teatro profissional Iondrino (1576-1603). Projeto História, v. 43, 517534, 2011.

SILBERBERG, T. Cultural tourism and business opportunities for museums and heritage sites. Tourism Management, v. 16, n. 5, 361-365, 1995,

SINGER, M. Traditional India: structure and change. Philadelphia: American Folklore Society, 1959.

SINGER, M. When a Great Tradition Modernizes. Chicago: University of Chicago Press, 1972.

SONG, H.; CHEUNG, C. Attributes affecting the level of tourist satisfaction with and loyalty towards theatrical performance in China: evidence from a qualitative study. International Journal of Tourism Research, v. 12, 665-679, 2010.

SONG, H.; CHEUNG, C. What makes theatrical performances successful in China's tourism industry? Journal of China Tourism Research, v. 8, 159-173, 2012.

STEBBINS, R. Cultural tourism as serious leisure. Annals of Tourism Research, v. 23, 948-950, 1996.

TOURISM TASMANIA. Arts Tourism Strategy 2012-2015. Tasmania: Tourism Tasmania, 2012.

TRAUER, B. Conceptualizing special interest tourism - frameworks for analysis. Tourism Management, v. 27, 183-200, 2006.

TURNER, V. 0 processo ritual: estrutura e antiestrutura. Petrópolis: Vozes, 1974.

VASCONCELLOS, L. P. Dicionário do Teatro. Porto Alegre: L\&PM Editores, 2009.

\section{Sobre as autoras}

Maria Manuel Baptista é docente e investigadora em Estudos Culturais no Departamento de Línguas e Culturas da Universidade de Aveiro e Diretora do Programa Doutoral em Estudos Culturais da Universidade de Aveiro ( $3^{\circ}$ ciclo lecionado em colaboração com a Universidade do Minho). Com obra diversa, publicada nacional e internacionalmente, na área dos Estudos Culturais, é doutorada em Cultura, pela Universidade de Aveiro, desde 2002, mestre em Psicologia da Educação pela Faculdade de Psicologia e Ciências da Educação da Universidade de Coimbra, 1996 e licenciada em Filosofia pela Faculdade de Letras da Universidade do Porto, 1986. Começou a sua atividade profissional em 1986 como jornalista e desde então lecionou e conduziu investigação em Estudos Culturais, nas áreas de intersecção entre as Ciências Humanas e Sociais. É Presidente da ONG IRENNE - Associação de investigação, prevenção e combate à violência e exclusão.

Vanessa Lamego é mestranda em Gestão e Planeamento em Turismo na Universidade de Aveiro, no ramo/percurso de Turismo e Cultura e licenciada em Turismo pela Universidade de Aveiro. 